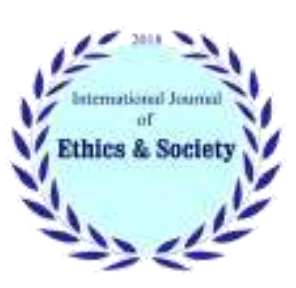

International Journal of Ethics \& Society (IJES)

Journal homepage: $\underline{\text { www.ijethics.com }}$

Vol. 2, No. 4 (2021)

\title{
Predicting Employee Productivity based on Work Ethics \& Organizational Learning
}

\author{
Samaneh Faregh ${ }^{\mathrm{a}}$, Ramezan Jahanian ${ }^{\mathrm{b} *}$, Mahtab Salimi ${ }^{\mathrm{b}}$ \\ a) Dept. of Educational Management, Karaj Branch, Islamic Azad University, Karaj, Iran. \\ b) Dept. of Educational Sciences, Karaj Branch, Islamic Azad University, Karaj, Iran.
}

\section{Abstract}

Background: Today, employee productivity is an important issue for organizations and the role of work ethics and learning in productivity is considered important. Therefore, the purpose of this study was to predict employee productivity based on work ethics and organizational learning.

Method: The method of the present study was descriptive-correlation. The statistical population included the employees of the Social Security Organization (404 people) whose sample size was selected based on Cochran's formula and random sampling method $(\mathrm{n}=205)$. The research instruments were Hersey and Blanchard (1983) employee productivity questionnaire, Gregory (1990) work ethic and Nife (2001) organizational learning questionnaire, the reliability of which was obtained by Cronbach's alpha test (0.84). Descriptive statistics were analyzed with SPSS26 software and inferential statistics were analyzed with Amos24.

Results: Data analysis showed that the variables of work ethic and organizational learning can predict 0.45 variance of the criterion variable (employee productivity). Also, work ethic and organizational learning had an impact factor of 0.51 and 0.43 , respectively, on employee productivity $(\mathrm{p}<0.05)$.

Conclusion: According to the results, it can be said that work ethic and organizational learning are effective on employee productivity. Therefore, to increase organizational productivity, more attention should be paid to work ethic and organizational learning.

Keywords: Work ethics, Employee productivity, Organizational learning

\section{Introduction}

The performance of an organization is consistently and significantly determined by the performance of processes and the performance of human re- sources. In fact, only by improving human resources can we expect the desired performance of the organization and thus productivity $(1,2)$. Studies show that under the same conditions, the only

* Corresponding Author: Email: ramezan.jahanian@yahoo.com

Received: 23 Dec 2020

Accepted: 28 Jan 2021

48

Available at: www.ijethics.com 
reason for organizational failure that causes the organization to fail to achieve its goals is the lack of productivity of human resources (3).

Employee productivity is one of the benefits of organizational excellence. Organizations try to identify the causes and factors of increasing the productivity of their employees so that they can achieve their organizational goals (4). Many factors in employee productivity have been considered by experts. Previously, it was believed that productivity could only be achieved through a set of material factors. In fact, high levels of access to finance and hardware lead to the productivity of organizations. But researchers now believe that human resources also play an important role in productivity (5). One of the important factors on employee productivity is work ethic (6). Work ethic in general can be defined as people's attitudes and beliefs about the value of work, work commitment and the degree of adherence to the principles of work profession (7). Employees' work ethic includes a set of values and ethical principles as a guide that can enhance their work performance. Work ethic does not simply mean applying specific philosophical methods to professional work; It is also the application of ethical principles and codes (8). The results of some studies have shown that work ethic can increase the level of responsibility of employees and this can also lead to better work performance of employees. Work ethic also makes employees look at their profession with a positive attitude and have a positive evaluation of it (9).

Another important factor in employee productivity is organizational learning. Organizational learning refers to an organization's ability to process knowledge through the acquisition, transfer and integration of knowledge and behavior modification, which ultimately leads to a new cognitive status with the aim of improving performance (10). Organizational learning in today's knowledge world, competitive advantage and competence are considered essential for the sustainability and dynamism of organizations (11). This type of learning helps organizations respond to changes in the organizational environment and leads to innovations that improve their performance (12). Organizational learning can be achieved in two forms: adaptive and productive learning. Adaptive learning requires unexpected behaviors that produce relatively specific behaviors and are influenced by the individual's reactions to similar situations in different environments. But productive learning deals with situations that add to new behaviors, the application of past knowledge and skills and their application in different and new situations (13).

Most productivity studies have been conducted in manufacturing and heavy industry organizations, and in service organizations such as the Social Security Organization have been rare and have formed a research vacuum. Research has shown that work ethic enhances the productivity of faculty members through creativity in work (14). Researchers found that work ethic has a positive, direct and significant effect on employees' job performance (15). In other studies, researchers concluded that employees' individual productivity has a significant relationship with work ethic and its dimensions (1617). Other researchers have concluded in similar results that organizational learning has a significant relationship with human resource productivity (1819). Another study showed that work ethic leads to improved organizational performance environment of employees (20). Other results showed that work ethic is related to productivity and quality of life of employees (21). In another similar study, researchers found that the quality of work ethic leads to improved job satisfaction and employee productivity (23-22). The results of other studies showed that organizational learning is one of the factors that have a positive effect on the performance of an organization (24). Other results showed that organizational learning has a mediating role in the relationship between strategic planning and organizational performance (25).

Productivity can occur in all manufacturing, distribution and service organizations. It is one of the service organizations of the Social Security Organization, which provides various support and insurance services to the general public, and productivity is an important issue in this organization. The literature shows that organizational learning is related to employee productivity; Professional ethics variables can also affect employee productivity. Some 
studies have shown that work ethic leads to increased work responsibility and this can lead to better work performance in employees. Despite the impact of these two variables on employee productivity, no research has been conducted in this field and in the social security community, and it has created a research gap. Therefore, the purpose of this study is to predict employee productivity based on professional ethics and organizational learning in the Social Security Organization.

\section{Material and Methods}

The method of the present study was descriptivecorrelational and in terms of purpose it was an applied research. The statistical population included the employees of the Social Security Organization of Qazvin province (440 people) in 2019. The sample size was determined based on Cochran's formula ( $\mathrm{n}=205)$. Random sampling method was also used to select the sample.

The research instrument included the following questionnaires: 1- Employee Productivity Questionnaire: This scale was designed in 1980 and has 7 components (ability, understanding and cognition, organizational support, motivation, feedback, credibility and adaptability) and 26 items based on the Likert scale is scored in 5 parts: very high (5), high (4), somewhat (3), low (2) and very low (1). Scores ranging from 26 to 43 are considered low productivity, ranges between 44 and 88 are considered average productivity and scores above 88 are highly productive (26). The validity and reliability of this questionnaire has been confirmed in internal studies such as Iranzadeh et al. (27). 2- Work ethic questionnaire: This scale was created in 1990 and has 4 dimensions (attachment and interest in work, perseverance and seriousness in work, healthy and humane relationships in the workplace and collective spirit and participation in work) and 23 items.
And according to the Likert scale (strongly disagree (1), disagree (2), neither agree nor disagree (3), agree (4) and strongly agree (5), the range of 23 to 46 indicates poor work ethic; Between 46 and 69, the level of work ethic at the intermediate level and scores above 69 means the level of work ethic is very good (28). In a study (29), the reliability of this questionnaire is 0.85 . Organizational Learning Questionnaire: This scale was developed in 2001 and has 7 dimensions (shared perspective, organizational culture, teamwork and learning, knowledge sharing, systems thinking, participatory leadership and staff competency development) and 33 items. The basis of the Likert scale is graded as very strongly agree (7), strongly agree (6), agree (5), neither agree (4), disagree (3), strongly disagree (2), very strongly disagree (1) (30). Reliability of this questionnaire had been reached in Khan Alizadeh's research $(0.83)$.

To analyze the data, descriptive statistical tests (mean, frequency and percentage) were analyzed with SPSS26 software and inferential data (structural equations) were analyzed with Amos24 software were used.

\section{Results}

Descriptive indicators (mean, standard deviation, minimum and maximum scores) of research variables are presented in table (1).

The findings of table (1) show that in the dimension of employee productivity, the component of ability (3.56), in the dimension of work ethic, the component of healthy relations in the workplace (4.25), in the dimension of organizational learning, the component of employee competence development (82/4) have obtained the highest average. Table 2 also examines the normality of the data.

Table1: descriptive indicators of research variables

\begin{tabular}{|l|l|l|l|l|}
\hline Factors/variable & \multicolumn{1}{c|}{ Mean } & SD & \multicolumn{1}{l|}{ Minimum } & Maximum \\
\hline Employee productivity & $2 / 66$ & $0 / 45$ & $1 / 11$ & $4 / 17$ \\
\hline Ability & $3 / 56$ & $0 / 98$ & $1 / 15$ & $4 / 53$ \\
\hline Clarity & $3 / 37$ & $0 / 84$ & $1 / 04$ & $4 / 29$ \\
\hline Organizational support & $2 / 23$ & $0 / 59$ & $1 / 07$ & $4 / 47$ \\
\hline Incentive & $2 / 35$ & $0 / 65$ & $1 / 18$ & $4 / 33$ \\
\hline Feedback & $2 / 11$ & $0 / 61$ & $1 / 21$ & $4 / 58$ \\
\hline
\end{tabular}




\begin{tabular}{|l|l|l|l|l|}
\hline Credit & $2 / 26$ & $0 / 63$ & $1 / 13$ & $4 / 11$ \\
\hline Compatibility & $2 / 76$ & $0 / 52$ & $1 / 04$ & $4 / 23$ \\
\hline work ethics & $3 / 16$ & $0 / 44$ & $1 / 16$ & $4 / 52$ \\
\hline Dependable & $3 / 25$ & $0 / 77$ & $1 / 19$ & $4 / 43$ \\
\hline Ambitious & $2 / 51$ & $0 / 62$ & $1 / 18$ & $4 / 39$ \\
\hline Healthy and humane relationships in the workplace & $4 / 25$ & $0 / 75$ & $1 / 14$ & $4 / 34$ \\
\hline Cooperative & $2 / 64$ & $0 / 68$ & $1 / 13$ & $4 / 19$ \\
\hline Organizational Learning & $3 / 82$ & $1 / 03$ & $1 / 56$ & $5 / 26$ \\
\hline Shared vision & $2 / 47$ & $1 / 31$ & $1 / 39$ & $5 / 34$ \\
\hline Organizational culture & $4 / 74$ & $1 / 34$ & $1 / 49$ & $6 / 35$ \\
\hline Teamwork and learning & $3 / 69$ & $2 / 08$ & $1 / 52$ & $6 / 10$ \\
\hline Shared knowledge & $3 / 15$ & $1 / 52$ & $1 / 78$ & $5 / 78$ \\
\hline Systematic thinking & $3 / 59$ & $1 / 62$ & $1 / 63$ & $6 / 25$ \\
\hline Participatory leadership & $4 / 29$ & $1 / 53$ & $1 / 48$ & $6 / 67$ \\
\hline Employee skills and competencies & $4 / 82$ & $1 / 53$ & $1 / 76$ & $6 / 55$ \\
\hline
\end{tabular}

Findings in table (2) show that the significance level of Shapiro-Wilkes test for all three main variables (employee productivity, work ethic and organizational learning) is more than 0.05 . Therefore, it can be said that the distribution of the main variables of the research is normal and the structural equation modeling method can be used to fit the conceptual model. Structural equation modeling helps the researcher to test and evaluate a theoretical model consisting of various components, both in general and in part (32). To investigate the model, first, confirmatory factor analysis was used to measure the relationships between hidden variables and their measurement items. The measurement model (confirmatory factor analysis) examines the relationship between the items or the same questions of the questionnaire with the structures. Then, using a structural model, the relationship between the factors and each other will be examined to test the hypotheses. In the present study, the factor validity of the questionnaire was done with the help of confirmatory factor analysis and using Amos software.

The fit indices of the measurement models are summarized in Table (3).

Table2: Results of checking the normality of the main dimensions of the model
\begin{tabular}{|l|l|l|l|l|l|l|}
\hline Variable & Shapiro-Wilk & Sig. & Skewness & Kurtosis & Results \\
\hline Employee productivity & $0 / 994$ & $0 / 627$ & $0 / 61$ & $0 / 32$ & Normal \\
\hline Work ethics & $0 / 993$ & $0 / 493$ & $0 / 62$ & $0 / 71$ & Normal \\
\hline Organizational learning & $0 / 996$ & $0 / 918$ & $0 / 47$ & $0 / 99$ & Normal \\
\hline
\end{tabular}

Table 3: Fit indicators for each of the measurement models

\begin{tabular}{|l|l|l|l|l|}
\hline Indicator & Optimum & Employee productivity & Work ethics & Organizational learning \\
\hline X2/df & 3 and less & $1 / 27$ & $1 / 43$ & $1 / 25$ \\
\hline RMR & Near zero & $0 / 080$ & $0 / 076$ & $0 / 038$ \\
\hline GFI & $0 / 9$ and more & $0 / 947$ & $0 / 934$ & $0 / 943$ \\
\hline AGFI & $0 / 9$ and more & $0 / 926$ & $0 / 912$ & $0 / 930$ \\
\hline NFI & $0 / 9$ and more & $0 / 938$ & $0 / 930$ & $0 / 925$ \\
\hline RFI & $0 / 9$ and more & $0 / 909$ & $0 / 945$ & $0 / 930$ \\
\hline IFI & $0 / 9$ and more & $0 / 912$ & $0 / 915$ & $0 / 919$ \\
\hline TLI & $0 / 9$ and more & $0 / 921$ & $0 / 905$ & $0 / 936$ \\
\hline CFI & $0 / 9$ and more & $0 / 947$ & $0 / 934$ & $0 / 943$ \\
\hline PRATIO & $0 / 5$ and more & $0 / 807$ & $0 / 508$ & $0 / 646$ \\
\hline PNFI & $0 / 5$ and more & $0 / 770$ & $0 / 530$ & $0 / 617$ \\
\hline PCFI & $0 / 5$ and more & $0 / 574$ & $0 / 707$ & $0 / 617$ \\
\hline RMSEA & Less than $0 / 08$ & $0 / 065$ & $0 / 060$ & $0 / 058$ \\
\hline
\end{tabular}


The results of confirmatory factor analysis showed that the measurement models have a good fit because the value of $\chi^{2} / \mathrm{df}$ (chi-square divided by the degree of freedom) is less than 3 , and the value of RMSEA is less than 0.08, the values of GFI, AGFI and NFI are greater than /9. 0 and economical indices (PNFI and PCFI) is more than 0.5. In the following, the validity and reliability of the model structures are examined.

Confirmatory factor analysis (CFA) was used to evaluate measurement models. For this purpose, the factor load of each indicator (item) on each structure was estimated and analyzed using its significance level. Thus, if the significance level is less than 0.05 , the factor loads are significant at the $5 \%$ level and the null hypothesis that the role of the marker in the formation of the studied structure is not significant is rejected and the significance of the relations in the form of analysis a confirmation factor is accepted. Also, for each structure, the two extracted mean variance (AVE) and combined reliability (CR) indices are calculated to measure the validity and reliability of the structures, respectively. AVE index shows what percentage of the variance of the studied structure was affected by the markers of that structure. The AVE index is used to measure the validity of a structure and is also known as convergent validity. Researchers have set a value of 0.5 or higher for the appropriateness of this index. Therefore, according to the extracted mean variance (AVE) index, values higher than 0.5 indicate the appropriate validity of the structure under study. The composite reliability (CR) method was used to determine the reliability of the structures. If the $\mathrm{CR}$ value for structures is greater than 0.6, they show acceptable reliability (32). In addition, Cronbach's alpha index $(\alpha)$ was used to evaluate the reliability of the structures. The results of confirmatory factor analysis and construct validity and reliability indices of measurement models are given in Table (4).

Table 4: Factor loads and construct validity and reliability indices

\begin{tabular}{|c|c|c|c|c|c|}
\hline Factors/variable & Factor loading & $P$ value & $\alpha$ (Chronbach) & CR & AVE \\
\hline Employee productivity & - & - & 0.811 & 0.915 & 0.827 \\
\hline Ability & 0.78 & $0.001<\mathrm{p}$ & & & \\
\hline Clarity & 0.75 & $0.001<\mathrm{p}$ & & & \\
\hline Organizational support & 0.73 & $0.001<\mathrm{p}$ & & & \\
\hline Incentive & 0.79 & $0.001<\mathrm{p}$ & & & \\
\hline Feedback & 0.76 & $0.001<\mathrm{p}$ & & & \\
\hline Credit & 0.78 & $0.001<\mathrm{p}$ & & & \\
\hline Compatibility & 0.85 & $0.001<\mathrm{p}$ & & & \\
\hline Work ethics & - & - & 0.872 & 0.864 & 0.811 \\
\hline Dependable & 0.76 & $0.001<\mathrm{p}$ & & & \\
\hline Ambitious & 0.79 & $0.001<\mathrm{p}$ & & & \\
\hline Healthy and humane relationships in the workplace & 0.73 & $0.001<\mathrm{p}$ & & & \\
\hline Cooperative & 0.85 & $0.001<\mathrm{p}$ & & & \\
\hline Organizational Learning & - & - & 0.849 & 0.926 & 0.855 \\
\hline Shared vision & 0.83 & $0.001<\mathrm{p}$ & & & \\
\hline Organizational Culture & 0.81 & $0.001<\mathrm{p}$ & & & \\
\hline Teamwork and learning & 0.80 & $0.001<\mathrm{p}$ & & & \\
\hline Shared knowledge & 0.75 & $0.001<\mathrm{p}$ & & & \\
\hline Systematic thinking & 0.84 & $0.001<\mathrm{p}$ & & & \\
\hline Participatory leadership & 0.83 & $0.001<\mathrm{p}$ & & & \\
\hline Employee skills and competencies & 0.74 & $0.001<\mathrm{p}$ & & & \\
\hline
\end{tabular}

The results of Table (4) show that the standardized factor load of all variables is more than 0.7 and is significant (significance level is less than 0.01). The value of the index (AVE) for all structures is more than 0.5 and the composite reliability index is more than 0.6. Cronbach's alpha value of all three constructs is more than 0.7 , so each of the model 
constructs has convergent validity and good composite reliability for measuring research variables. Figure 1 also shows the final structural model.

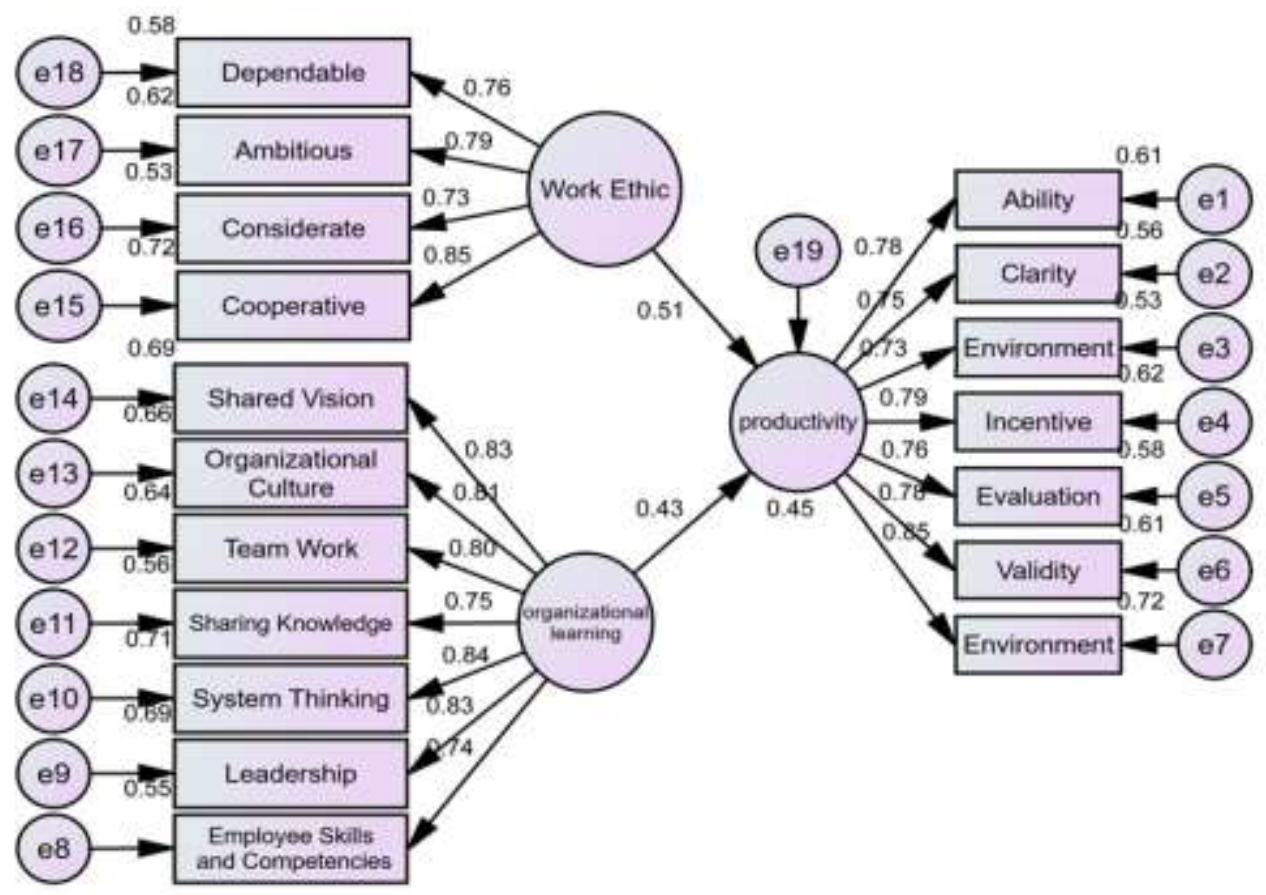

Figure 1: Fitted structural model of employee productivity

Findings in the structural model (Figure 1) show that the factor load of the components in all dimensions is greater than 0.7 , which shows that the components explain the dimensions well. The coefficient of determination of the employee productivity variable is equal to 0.45 , which means that $45 \%$ of the changes in employee productivity can be explained by two independent variables "work ethic" and "organizational learning". Table (5) shows the suitability indicators of the model. Fit indicators in table (5) show that all indicators are in the desired range, so the structural model of the research is approved. Table (6) also shows the significance of the path coefficient and the level of significance between the main variables.

Table 5: Fitness indicators of the research model

\begin{tabular}{|c|c|c|c|c|c|c|c|}
\hline Fitness indicators & $\chi 2 / \mathrm{df}$ & RMSEA & CFI & TLI & IFI & GFI & AGFI \\
\hline Reported value & 1.28 & 0.0434 & $0 / 908$ & $0 / 921$ & $0 / 959$ & $0 / 947$ & $0 / 941$ \\
\hline Accepted value & Less than 3 & $0.08<$ & $0.09<$ & $0.09<$ & $0.09<$ & $0.09<$ & $0.8<$ \\
\hline
\end{tabular}

Table 6: Significance of path coefficients

\begin{tabular}{|l|l|l|l|l|}
\hline Relationship & $\boldsymbol{\beta}$ & CR & $\boldsymbol{\alpha}$ & \multicolumn{1}{l|}{ Result } \\
\hline Work ethics and employee productivity & 0.51 & 6.28 & 0.001 & Significant \\
\hline Organizational learning and employee productivity & 0.43 & 5.64 & 0.001 & Significant \\
\hline
\end{tabular}

The results of Table (6) show that the value of work ethic coefficient with employee productivity is equal to 0.51 . Also, the value of organizational learning path coefficient with employee productiv- ity is equal to 0.43 and both coefficients are significant at 95\% confidence level, so ethics variables Work and organizational learning have a positive and significant effect on employee productivity. 


\section{Discussion}

The main purpose of this study was to predict employee productivity based on work ethic and organizational learning in Qazvin Social Security Organization. Findings showed that work ethic and organizational learning have a significant relationship with employee productivity and both variables predicted 0.45 variance of criterion variable (employee productivity) $(\mathrm{p}<0.05)$. The results of the present study are in line with some studies and studies that concluded that work ethic has a significant relationship with employee productivity (1417, 23-20). In explaining the effect of work ethic on employee productivity, it can be said that work ethic is a kind of inner desire and attitude to observe ethical and work norms. Ethics in work creates a kind of commitment; if a person has a higher level of work ethic, he becomes more sensitive to the protection of the property and rights of others, his group and organization. Therefore, it can be concluded that work ethic creates a kind of commitment and responsibility towards oneself, others and even groups, which ultimately forms a positive attitude in the individual and leads to better performance. In addition, some research has shown that the spirit of cooperation and partnership as one of the important components of work ethic leads to greater productivity by increasing the spirit of sharing and sharing knowledge among employees (33). A collaborative spirit distributes all learning capacity among employees, resulting in better employee performance.

Organizational learning also had a significant relationship with employee productivity. This finding is in line with the results of some studies that have found that organizational learning leads to improved employee productivity and confirms their results $(25,24,19,18)$. Explaining the results, it should be said that organizational learning is one of the variables that organizations teach their employees how to learn and share knowledge in a group and share their experiences. In such a situation, employees will feel more responsible for each other. In fact, the synergy of learning experiences makes employees have a higher level of performance. This can be one of the effective factors in improving organizational performance and consequently their productivity. Another is that in the shadow of sharing organizational learning, we can see a reduction in organizational and psychological costs. This cost reduction actually generates more employee efficiency. Organizational learning by sharing experiences inside and outside the organization allows employees to solve problems and problems in the shortest possible time and provide the best solutions instead of individually searching for the necessary information, which is associated with cost and waste of client time.

The findings of the present study, like other studies, had some limitations. This research was a case study and to generalize the results, research at a larger level is needed. Another limitation was that other interfering factors in the research may have been outside the researcher's control. Another limitation is that only a small method was used in this study, while the combined method has more advantages. Therefore, it is suggested that researchers in future studies to study the productivity of employees based on work ethic and organizational learning to explore the components of variables. Another suggestion is to strengthen the work ethic of employees by providing material and extra-material rewards for employees who are more attached to their work and are more ethical in nature. Due to the effectiveness of organizational learning in improving productivity, setting up working groups of two or more people in organizations and departments to improve knowledge and skills and to encourage them, benefits and rewards should be considered.

\section{Conclusion}

It can be concluded that employee productivity is affected by many factors. Meanwhile, work ethic and organizational learning affect employee productivity. In other words, by strengthening the work ethic variable, more productivity can be witnessed in employees. Also, supplementing work ethic, strengthening organizational learning and 
paying attention to employee learning can lead to greater employee productivity.

\section{Ethical Consideration}

In order to observe the research ethics, the purpose of the research was explained to the respondents and it was also ensured that the research findings are for research work and will not be made available to anyone other than the researcher. It was also mentioned in the letter attached to the questionnaire that if the respondent does not want to complete the questionnaire, he can return it.

\section{Acknowledgement}

The researcher would like to thank all the dear employees of the Social Security Organization of Qazvin Province who completed the questionnaires. Thanks also to other professors who provided helpful tips to the researcher.

\section{References}

1. Simanova L, Sujova, A, Gejdos P (2019). Improving the performance and quality of processes by applying and implementing six sigma methodology in furniture manufacturing process. Wood Industry/Drma Industrija, 70(2): 193.

2. Lee F, Lee T, Wu W (2010). The relationship between human resource management practices, business strategy and firm performance: evidence from steel industry in Taiwan. The International Journal of Human ResourceManagement, 21(9): 1351-1372

3. Thudaa A, Sarib J, Maharanic A (2019). Employees perception of human capital practices, employee's productivity, and company performance. Integrated Journal of Business and Economics, 3(3): 240-250.

4. Gyurák Babel'ová Z, Stareček A, Koltnerová K, Cagáňová D (2020). Perceived organizational performance in recruiting and retaining employees with respect to different generational groups of employees and sustainable human resource management. Sustainability, 12(2): $574-488$

5. Van Ness RK, Melinsky K, Buff CL, Seifert CF (2010). Work ethic: Do new employees mean new work values? Journal of Managerial Issues, 1: 10-34

6. Sapada AFA, Modding HB, Gani A, Nujum S (2018). The effect of organizational culture and work ethics on job satisfaction and employees performance. The International Journal of Engineering and Science (IJES), 6(12): 28-36.
7. Osibanjo AO, Akinbode J, Falola HO, Oludayo OO (2018). Work ethics and employees' job performance. Journal of Leadership, Accountability and Ethics, 12(1): 107-117.

8. Bozovic J (2007). Business ethics banking. Economics and Oryanization, 4(2):173- 182.

9. Rokhman W (2010). The effect of Islamic work ethics on work outcomes. EJBO-Electronic Journal of Business Ethics and Organization Studies, 15(1): 21-27.

10. Pham LT, Hoang HV (2019). The relationship between organizational learning capability and business performance. Journal of Economics and Development, 21(2): 269-259.

11. Namada JM (2018). Organizational learning and competitive advantage. SAGE Publication, California/USA. Pp. 86-104.

12. Sisaye S, Birnberg JG (2012). Oryanizational learning and process innovations: an integrated framework. Emerald Group Publishing Limited, UK.

13. Peng H, Ma S, Spector JM (2019). Personalized adaptive learning: an emerging pedagogical approach enabled by a smart learning environment. Smart Learning Environments, 6(1): 9-21

14. Azizinazhad B (2019). Analyzing of the relationships between work ethics and organizational commitment by meditating organizational justice. Ethics in Science and Technology, 14 (2):144-148. (In Persian).

15. Sagheb Esmaeelpour M, Abdi K, Hosseini M A, Biglarian A (2019). The relationship of work ethics with job performance of the administrative and medical staff of the university of social welfare and rehabilitation sciences and its affiliated centers in 2017. JREHAB, 20(1): 52-63. (In Persian).

16. Dargahi H, Moamaei H (2017). The relationship between job ethics and staffs productivity in Tehran University of Medical Sciences. IJME, 10 (1):103-118. (In Persian).

17. Rahmani H, Rajabdoory H (2016). Investigating the impact of professional ethics on organizational performance in industrial managers of Fars province. $A A P C, 1$ (1): 5375. (In Persian).

18. Jalali Farahani M, Freydoni M, Zafari R (2017). Designing a model of the effect of organizational culture on organisational learning and human resources efficiency. Organizational Behavior Management in Sport Studies, 4(13): 41-48. (In Persian).

19. Hatami S, Dastar H (2012). Verifying the role of learning in human resource productivity through empowerment. Human Resource Management Research, 4(1): 27-54. (In Persian).

20. Salahudin SN, Alwi MN, Baharuddin SS, Halimat SS (2016). The relationship between work ethics and job performance. Proceedings, 465-471. 
21. Kumara P, Dutta M (2019). Impact of work ethics on QWL, productivity and corporate image of an organization. IOSR Joumal of Humanities and Social Science (IOSRJHSS), 24(4): 33-39.

22. Panigrahi S, Al-Nashash HM (2019). Quality work ethics and job satisfaction: an empirical analysis. Quality Access To Success, 20: 41-47.

23. Nasution F, Rafiki A(2020). Islamic work ethics, organizational commitment and job satisfaction of Islamic banks in Indonesia. R AUSP Management Journal, 55(2): 195-205

24. Tafvelin S, von Thiele Schwarz U, Hasson H (2017). In agreement? Leader-team perceptual distance in organizational learning affects work performance. Journal of Business Research, 175):1-7.

25. Rao SA, Burde JK(2017). A Hindu perspective to organizational leaming. The Learning Organization, 24(()) 386-391.

26. Hersey P, Goldsmith HM (1980). The ACHIEVE system: a buman performance problem-solving model. Jossey-Bass Publication, USA.

27. Iranzadeh S, Zemestani G, Pakdel Bonab M, Babaye heravi $S$ (2013). Investigating the relationship between organizational health and personnel productivity of the staff working at Islamic Azad University, Tabriz Branch. Productivity Management, 7(24): 49-70. (In Persian).
28. Petty GC (1995). Vocational-technical education and the occupational work ethic. Journal of Industrial Teacher Education, 32(3).

29. Golparvar M, Nadi MA (2011). Mediating role of organizational loyalty in relation between work ethic with deviant workplace behavior. Ethics in Science and Technology, 6 (1): 4353. (In Persian).

30. Khanalizadeh R, Kordnaiej A, Asghar Fani A, Moshabaki A (2010). Study of the relationship between organizational learning and empowerment. Jounnal of Transformation Management, 2(3); 21-45.

31. Neefe D (2001). Comparing levels of organizational learning maturity of colleges and universities participating in traditional and nontraditional (academic quality improvement project) accreditation processes. University of Wisconsin Stout, Wisconsin /USA. Pp.1-130.

32. Ghasemi V (2010). Structural equation modeling in social reseanh using AMOS graphics. Sociologists Publications, Tehran/Iran. (In Persian)

33. Noghani M, Massoudi H (2011). Participation in the field of strategic management and productivity group activities. Strategic Management Studies, 2(8): 15-34. (In Persian). 